\title{
Rulmanlı Yatak Uygulamaları İçin Grafit Katkılı PTFE ve PTFE Katkılı Poliamit-6 Polimerlerinin Aşınma ve Sürtünme Performanslarının Karşılaştırılması
}

\author{
Hüseyin ÜNAL ${ }^{* 1(D,}$, Salih Hakan YETGİN2 ${ }^{(1)}$

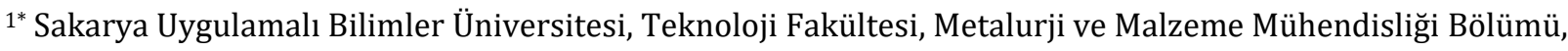 \\ Sakarya, Türkiye \\ ${ }^{2}$ Tarsus Üniversitesi, Mühendislik Fakültesi, Makine Mühendisliği Bölümü, Mersin, Türkiye
}

(Alınış / Received: 16.12.2020, Kabul / Accepted: 25.05.2021, Online Yayınlanma / Published Online: 15.08.2021)

\author{
Anahtar Kelimeler \\ Polimer, \\ Triboloji, \\ Poliamit, \\ PTFE, \\ Grafit
}

\begin{abstract}
Özet: Bu çalışma, rulmanlı yatak uygulamalarında kullanılan ağırlıkça \%35 grafit katkılı politetrafloretilen (35G/PTFE) kompozit ve ağırlıkça \%10 PTFE katkılı poliamit 6 (10PTFE/PA6) polimer karışımının farklı hızlar altındaki tribolojik performanslarının karșılaștırılması amacıyla gerçekleștirilmiștir. Tribolojik deneyler, $1.0,1.5$ ve $2.0 \mathrm{~m} / \mathrm{s}$ kayma hızlarında, $50 \mathrm{~N}$ ve $150 \mathrm{~N}$ yükler altında disk üzerinde pim olan bir aşınma test düzeneğinde gerçekleştirilmiştir. Deneyler, AISI 316L paslanmaz çelik disk malzemeye karşı kuru kayma şartları altında, oda sıcaklığında yapılmıștır. Așınma ve sürtünme deneyleri sonucunda, kayma hızının artması ile deneylerde kullanılan her iki malzemenin sürtünme katsayısının çok az etkilendiği gözlenirken aşınma hacmi ve aşınma oranı değerlerinin arttığı gözlenmiştir. Elde edilen veriler sonucunda, \%35 grafit katkılı PTFE kompozitin aşınma oranı 2.70 ile $3.67 \times 10^{-14} \mathrm{~m}^{2} / \mathrm{N}$ aralığında elde edilirken \%10 PTFE katkılı PA6 polimer karışımının aşınma oranını ise 5.07 ile $15.5 \times 10^{-14} \mathrm{~m}^{2} / \mathrm{N}$ aralığında elde edilmiştir. \%35 grafit katkılı PTFE kompozitinin aşınma oranı \%10PTFE katkılı PA6 polimer karışımına göre ortalama \%62 oranında daha az aşındığı tespit edilmiştir.
\end{abstract}

\section{Comparison of Wear and Friction Performance of Graphite filled PTFE and PTFE Filled Polyamide Polymers for Bearing Applications}

Keywords

Polymer,

Tribology,

Polyamide,

PTFE,

Graphite

\begin{abstract}
This study was carried out to compare the tribological performances of $35 \mathrm{wt} . \%$ graphite-added polytetrafluoroethylene (35G/PTFE) composite and 10wt.\%PTFE filled polyamide 6 (10PTFE/PA6) polymer blend at different speeds used in rolling bearing applications. Tribological tests were carried out on a pinon-disc wear test rig at the sliding speeds of $1.0,1.5$ and $2.0 \mathrm{~m} /$ and under the loads of $50 \mathrm{~N}$ and $150 \mathrm{~N}$. Tests were conducted against AISI 316L stainless steel disc material under dry sliding conditions at room temperature. As a result of the wear and friction tests, it was observed that the coefficient of friction values of both materials used in the experiments was slightly affected by the increase in sliding speed, while the wear volume and wear rate values increased. As a result of the obtained data, the wear rate of $35 \mathrm{wt} . \%$ graphite filled PTFE composite is between 2.70 and $3.67 \times 10^{-14} \mathrm{~m}^{2} / \mathrm{N}$, while the wear rate of $10 \mathrm{wt} . \%$ PTFE filled PA6 polymer blend is 5.07 to $15.5 \times 10^{-14} \mathrm{~m}^{2} / \mathrm{N}$. 35\% graphite filled PTFE composite was found to be average $62 \%$ wear resistant than that of $10 \mathrm{wt} . \%$ PTFE filled PA6 polymer mixture.
\end{abstract}

\section{Giris}

Polimer ve polimer esaslı kompozit malzemeler otomotiv, makine, kimya, elektrik/elektronik ve uzay endüstrisi gibi birçok endüstriyel uygulamada artan bir șekilde kullanılmaktadır. Bunun nedeni ise bu malzemelerin geleneksel malzemelere klyasla yüksek mukavemet/ağırlık oranı sağlamasıdır. Bununla birlikte, polimer malzemelerin düşük mekanik, termal ve tribolojik özellik göstermelerinden dolayı endüstride kullanım alanlarını sınırlamaktadır. Bu yüzden polimer malzemelerin mekanik ve termal 
özelliklerini geliştirmek için talk, kalsit, kaolin, cam bilya gibi katkı malzemeleri veya cam elyaf, karbon elyaf ve aramit elyaf gibi takviye edici katkı malzemeleri ilave edilir. Buna ilaveten tribolojik özellikleri geliştirmek için ise katı yağlayıcı adı verilen molibden disülfit $\left(\mathrm{MoS}_{2}\right)$, politetrafloretilen (PTFE), grafit ve vaks gibi katkılar kullanılmaktadır [1]. Bu katı yağlayıcılar arasında yer alan grafit, karbon atomunun bir formudur ve tabakalı bir yapıya sahiptir. Birbirine zayıf Van der Waals bağları ile bağlı olan bu tabakalar, kuvvet uygulandığında kolaylıkla birbiri üzerinden kayabilmektedir. Grafit gibi katı yağlayıcıların, temas eden iki yüzey arasında sürekli transfer film tabakası oluşturarak sürtünme katsayısını azalttığı belirtilmiştir.

Politetrafloretilen, kendinden yağlamalı özelliği, düşük sürtünme katsayısı, yüksek termal kararlılığı ve kimyasal dayanımı ile endüstrinin farklı alanlarında kullanım alanı bulan yüksek performanslı mühendislik plastiklerinden birisidir [2-5]. Ancak, PTFE düşük aşınma ve abrazif direnç gösterirler ve makine parçalarında erken arıza ve sızıntı problemlerine yol açmaktadır [6]. Bu problemleri minimize etmek için farklı katkılar kullanılmaktadır. Literatürde, cam elyaf, karbon elyaf, grafit, karbon, bronz veya katı yağlayıcı gibi katkıların PTFE polimerine ilave edildiği ve tribolojik özelliklerin incelendiği çalışmalar mevcuttur [1-10]. Reza ve Andreas [10] ağırlıç̧a \%10 grafit katkılı politetrafloretilen ve ağırlıkça \%15 grafit katkılı poliimid (PI) kompozitlerin $6.32 \mathrm{MPa}$ temas basıncında ve $1.91 \mathrm{~m} / \mathrm{s}$ kayma hızında disk üzerinde pim sistemi ile IS046 yağlayıcı ve 4200ppm silika yağlayıcı ortamındaki tribolojik özelliklerini incelemişlerdir. 4200ppm silika yağlayıcı ortamında daha yüksek sürtünme katsayısı elde edildiği belirtilmiştir. Prakash ve arkadaşları [2] ağırlıkça \%10, 20 ve 30 grafit katkılı PTFE kompozitlerin pimdisk sistemi ile $50 \mathrm{~N}$ yük ve $0.8 \mathrm{~m} / \mathrm{s}$ kayma hızı altındaki tribolojik özelliklerini incelemişlerdir. Çalışma sonucunda, PTFE polimerine ilave edilen grafit oranının artması ile polimer kompozitin sürtünme katsayısı ve aşınma oranının azaldığı belirtilmiştir. En yüksek aşınma direnci \%30 grafit katkılı PTFE kompozit malzemede elde edilmiştir. Wladyslaw ve arkadaşları [1] \%25 karbon katkılı PTFE, \%25 bronz ve \%15grafit katkılı PTFE, \%15 cam elyaf takviyeli PTFE ve \%40 bronz katkılı PTFE kompozitlerin tribolojik özelliklerini incelemişlerdir. Deneylerde kullanılan yük ve hız aralıklarında \%40 bronz katkılı PTFE polimerinin \%25 grafit katkılı PTFE polimerine göre daha uygun malzeme olduğu belirtilmiştir. Raaj ve arkadaşları [3] \%2.5, 7.5, 12.5, 17.5, 22.5 oranında $\mathrm{MoS}_{2}$ molibden disülfit katkılı \%2.5 Grafit ilaveli PTFE kompozitlerin aşınma ve sürtünme özelliklerini incelemişlerdir. Çalışmalarında katkı oranının, uygulanan yükün (10, $20,30 \mathrm{~N})$ ve kayma hızının $(1.18,1.19$ ve $1.20 \mathrm{~m} / \mathrm{s})$ tribolojik özelliklere etkileri incelenmiştir. Artan kayma hızı ile birlikte spesifik aşınma oranı azalırken yükün artması ile sürtünme katsayısı azalmıştır. PTFE polimerine ilave edilen grafit ve $\mathrm{MoS}_{2}$ katkıların aşınma direncini önemli oranda artırmıștır. Prashant ve Deore [6] ağırlıkça \%20 karbon katkılı PTFE, \%20 bronz katkılı PTFE ve ağırlıkça \%35 bronz katkılı PTFE kompozitlerin farklı yükler $(1,2,3 \mathrm{~kg})$, farklı kayma hızları $(600,800,1000 \mathrm{dev} / \mathrm{dk}$.) ve farklı kayma mesafelerinde $(2,3,4 \mathrm{~km})$ tribolojik özelliklerini incelemişlerdir. Artan yük miktarı ile tüm numunelerde sürtünme katsayısı ve aşınma oranı artmıştır. Artan kayma hızı ile sürtünme katsayısı artarken aşınma oranı azalmıştır. Kayma mesafesinin tribolojik özellikleri etkileyen en önemli parametre olduğu belirlenmiştir. \%20 karbon katkılı PTFE kompozitin aşınma direncinin \%20 bronz katkılı PTFE kompozitinden daha yüksek olduğu belirtilmiştir. En yüksek sürtünme katsayısı \%35 bronz katkılı PTFE kompozitinde elde edilmiștir. Mohammad ve arkadaşları [4] ağırlıç̧a \%25 cam elyaf katkılı PTFE kompozitlerin AISI 420 paslanmaz çelik diske karşı açlk havada, saf suda ve deniz suyundaki tribolojik özelliklerini incelemişlerdir. Cam elyaf takviyeli PTFE polimer kompozitin deniz suyu ortamında çok daha üstün tribolojik performans özellikleri gösterdiği belirtilmiştir. En düşük sürtünme katsayısı (0.028) ve en düşük aşınma oranı $\left(5.85 \times 10^{-6} \mathrm{~mm}^{3} \mathrm{Nm}^{-1}\right)$ deniz suyu ortamında elde edilmiştir. Bunun sebebinin ise disk yüzeyinde yağlayıcı film tabaksının oluşması olarak açıklanmıștır. Khan ve arkadaşları [7] yaptıkları bir başka çalışmada ise ağırlıkça \%60 bronz katkılı PTFE kompozitlerin AISI 420 paslanmaz çelik diske karşı açlk havada, saf suda ve deniz suyundaki tribolojik özelliklerini incelemişlerdir. Bronz katkılı PTFE kompozitin deniz suyu ortamında çok daha üstün tribolojik performans özellikleri gösterdiği belirtilmiştir. En düşük sürtünme katsayısı (0.0045) ve en düşük spesifik aşınma oranı $\left(1.10 \times 10^{-5}\right.$ $\mathrm{mm}^{3} / \mathrm{Nm}$ ) deniz suyu ortamında elde edildiği belirtilmiştir. Kumar ve arkadaşları [8] \%21, 22, 23 ve 24 oranlarında grafit katkılı PTFE kompozitlerin farklı yük (10 ve 20N) ve kayma hızları (190 ve 210dev/dk.) altında tribolojik özelliklerini incelemişlerdir. PTFE polimerine ilave edilen grafit aşınma oranını azaltmıştır. Bunun sebebi ise kompozitin yük taşıma kapasitesinin artmasına bağlanmıştır. Optimum aşınma oranı \%22 grafit miktarında $10 \mathrm{~N}$ yük ve $210 \mathrm{dev} / \mathrm{dk}$. kayma hızında elde edilmiştir. Sujuan ve Xingrong [5] bronz, cam elyaf, karbon elyaf, karbon, grafit ve polifenil ester (POB) katkılı PTFE kompozitlerin ortam sıcaklığındaki ve yüksek sıcaklıklardaki $(100,150$ ve $180^{\circ} \mathrm{C}$ ) aşınma ve sürtünme performanslarını incelemişlerdir. Çalışma sonucunda, aşınma direncinin ilave edilen katkılar ile arttığı belirtilmiştir. Katkısız PTFE polimerinin ortam sıcaklığında en düşük sürtünme katsayısına sahip olduğu ancak artan sicaklık ile birlikte yüksek sürtünme katsayısı elde edildiği belirtilmiştir. Bronz katkılı PTFE polimer kompozit malzeme ortam sıcaklığında en iyi aşınma direnci gösterirken yüksek 
sıcaklıklarda aşınma özellikleri kötüleşmiştir. Karbon, grafit ve POB katkılı PTFE kompozitler hem ortam hem de yüksek sıcaklıklarda düşük sürtünme katsayısı ve orta seviye aşınma direnci göstermişlerdir. Şahin ve Mirzayev [9] ağırlıkça \%60 bronz, \%25 karbon katkılı ve \%15 cam elyaf takviyeli PTFE kompozitlerin kuru ortam şartlarındaki aşınma özelliklerini incelemişlerdir. Aşınma testleri pim-disk aşınma cihazında gerçekleștirilmiştir. Aşınma testleri sonucunda, cam elyaf takviyeli kompozitin bronz ve karbon elyaf takviyeli kompozite göre aşınma direncinin daha yüksek olduğu, artan kayma mesafesi ve uygulanan yük ile birlikte aşınma oranının arttığ belirtilmiştir.

Poliamid 6 (PA6) polimeri, üstün mukavemet, sertlik, tokluk, darbe ve tribolojik özellikleri nedeniyle makine, elektrik/elektronik, otomotiv, kimya, ambalaj ve tekstil gibi sektörlerde mil yatak burçları, dişliler, contalar ve kasnak yapımında en çok tercih edilen mühendislik plastiklerinden birisi olmuştur. Zayıf olan özellikleri iyileştirmek için ise poliamit esaslı polimer malzemeye bazı katkılar ve mukavemet artırıcı katkılar ilave edilerek kullanım alanı geliştirilmektedir [11-13]. Umesh ve arkadaşları [14] ağırlıkça \%10PTFE katkılı PA6/PA66 karışımının tribolojik özellikleri üzerine uygulanan yük $(25,50,75$ ve $100 \mathrm{~N})$ ve kayma hılarının $(0.5$, $1.0,1.5$ ve $2.0 \mathrm{~m} / \mathrm{s}$ ) etkisini incelemişlerdir. Çalışma sonucunda, kayma hızının artması ile aşınma oranının arttığı belirtilmiştir. . Yükün artması ile aşınma hacmi artarken spesifik aşınma oranı azalmıştır. Ayrıca, PTFE'in tribolojik uygulamalar için en iyi malzeme olduğu ve çelik disk yüzeyinde oluşan transfer film tabakasının tribolojik özelliklerin belirlenmesinde önemli bir faktör olduğu belirtilmiştir. Li [15] tarafından yapılan PTFE ve PA6 kompozitlerinin yağlı ortamdaki tribolojik özelliklerinin incelendiği çalışma sonucunda da artan yüke bağlı olarak sürtünme katsayısının ve aşınma hacminin arttığı belirtilmiştir. Du-Xin ve arkadaşları da [16] PTFE ve çok yüksek moleküler ağırlıklı polietilen (ÇYMAPE) katkılı cam elyaf/PA6 (15/85\%) kompozitlerinin tribolojik özelliklerini inceledikleri çalışma sonucunda $40 \mathrm{~N}$ yük ve $200 \mathrm{dev} / \mathrm{dk}$. hızda PTFE polimerinin matris malzemelerin tribolojik özellikleri geliștirmede ÇYMAPE polimerinden daha etkili olduğu belirtilmiştir. Optimum aşınma direnci \%20 PTFE içeriğinde elde edilmiştir. Sürtünme katsayısında ve aşınma oranında sırasıyla \%30 ve \%29 oranında azalma elde edilmiştir. Kumar ve Kanagaraj [17] ağırlıkça \%5-40 oranlarında grafit katkılı PA6 polimerinin pim-disk sistemi kullanarak $5,10,20$ ve $30 \mathrm{~N}$ yük ve 1000,1500 ve $2000 \mathrm{dev} / \mathrm{dk}$. kayma hızlarındaki tribolojik özelliklerini incelemişlerdir. Çalışma sonucunda artan yük ile birlikte sürtünme katsayısı ve aşınma oranı azalmıştır. \%20 grafit katkılı PA6 kompoziti en iyi tribolojik özellikleri göstermiştir. Satheeskumar ve Kanagaraj [18] ağırlıkça \%5-30 oranlarında alüminyum oksit $\left(\mathrm{Al}_{2} \mathrm{O}_{3}\right)$ ve grafit katkılı PA6 kompozitlerinin pim-disk sistemi ile kuru ortamda tribolojik özelliklerini incelemişlerdir. Çalışmada, 5, 10,20 ve $30 \mathrm{~N}$ yük ile 1000 ve $2000 \mathrm{dev} / \mathrm{dk}$. kayma hızı kullanılmıștır. PA6 polimerine ilave edilen $\mathrm{Al}_{2} \mathrm{O}_{3}$ ve grafit tribolojik özellikleri önemli oranda geliştirmiştir. \%20 grafit ve $\% 30 \mathrm{Al}_{2} \mathrm{O}_{3}$ içeren PA6 kompozitleri kuvvetli arayüzey bağlanması nedeniyle en iyi tribolojik özellikleri göstermiştir. Kayma hızının artmasıyla sürtünme katsayısının ve așınma oranının arttığı belirlenmiştir. Artan yük miktarı ise polimerin aşınma oranını azaltırken ısı üretimini artırmıştır. Yi-Lan ve arkadaşları [19] talk, cam elyaf, grafit ve yüksek moleküler ağırlıklı polietilen (UHMWPE) katkılı PA6 polimerinin tribolojik özelliklerini incelemişlerdir. \%15 cam elyaf miktarında sürtünme katsayısı ve aşınma oranı azalmıştır. $\% 20$ ve 25 cam elyaf katkılı PA6 kompozitler hariç artan yük miktarı ile sürtünme katsayısı ve aşınma oranı artmıştır. Katı yağlayıcı olarak ilave edilen grafit ve UHMWPE sürtünme katsayısını ve aşınma oranını artırmıştır. Srinivas ve arkadaşları [20] ağırlıkça \%10-15-20-25-30 grafit katkılı PA6 polimerinin abrazif aşınma ve sürtünme özelliklerini incelemişlerdir. 5-10-15N yük altında pim-disk sistemi ile gerçekleştirilen aşınma testleri sonucunda artan yüke ve grafit oranına bağlı olarak spesifik aşınma oranın azaldığı belirlenmiștir. Çalışmalarında en düșük aşınma oranı \%25 grafit katkılı PA6 polimer kompozitinde elde edilmiştir. Endüstride yaygın kullanılan grafit katkılı PTFE polimerlerine alternatif olacak PTFE katkılı poliamit 6 polimeri kompound makinasında üretilerek aşınma ve sürtünme performansları geliștirilmiștir. Yapılan literatür incelemeleri Tablo 1'de özetlenmiştir.

Bu deneysel çalışmada, ağırlıkça \%35 grafit katkılı PTFE polimer kompoziti ve ağırlıkça \%10PTFE katkılı poliamit 6 polimer karışımı malzemeler kullanılmıştır. Tribolojik testler için pim-disk aşınma test cihazı kullanılmıștır. Rulmanlı yataklarda mil dönme hızı kullanılan polimer yatağın așınma ve sürtünme davranıșlarını etkilemekte ve malzemenin ömrünü belirlemektedir. Bu amaçla tribolojik testler, $1.0,1.5$ ve $2.0 \mathrm{~m} / \mathrm{s}$ kayma hızlarında, $50 \mathrm{~N}$ ve $150 \mathrm{~N}$ yükler altında kuru kayma şartlarında gerçekleştirilmiştir. Çalışmada elde edilen test sonuçlarına göre, kayma hızı arttığında deneylerde kullanılan her iki malzemenin hem sürtünme katsayısı hem de spesifik aşınma oranı değerleri hafif artış göstermiştir. 35G/PTFE kompoziti ve 10PTFE/PA6 polimerleri arasında en iyi aşınma direncini 35G/PTFE kompoziti göstermiştir. 35G/PTFE polimerinin aşınma direnci 10PTFE/PA6 polimer karışımına göre kıyaslandığında yaklaşık \%62 oranında daha yüksek olduğu tespit edilmiștir. 
Tablo 1. Grafit ve PTFE polimerler için literatür taraması ve sonuçları

\begin{tabular}{|c|c|c|c|c|c|c|c|}
\hline Referans & Test türü & Katkının türü & $\begin{array}{l}\text { Karşı disk } \\
\text { malzemesi }\end{array}$ & Yük & Kayma Hızı & $\begin{array}{l}\text { Kayma } \\
\text { mesafesi,m }\end{array}$ & $\begin{array}{l}\text { Sürtünme } \\
\text { katsayısı }\end{array}$ \\
\hline 2 & Pim-disk & \%10-20-30 Grafit/PTFE & - & $50 \mathrm{~N}$ & $0.8 \mathrm{~m} / \mathrm{s}$ & - & \begin{tabular}{l|l}
$\% 32.22$ azaldı & $\% 3536$ azaldı.
\end{tabular} \\
\hline 3 & Pim-disk & $\begin{array}{l}\% 2.5,7.5,12.5,17.5,22.5 \\
\mathrm{MoS}_{2} / \% 2.5 \text { Grafit+PTFE }\end{array}$ & - & $\begin{array}{l}10,20,30 \\
N\end{array}$ & $\begin{array}{l}1.18,1.19 \\
1.20 \mathrm{~m} / \mathrm{s}\end{array}$ & 2000 & $\begin{array}{l}\text { Artan kayma hızı ile birlikte spesifik } \\
\text { aşınma oranı azalırken yükün } \\
\text { artması ile sürtünme katsayısı } \\
\text { azalmıştır. PTFE polimerine ilave } \\
\text { edilen grafit ve MoS katkıların } \\
\text { aşınma direncini önemli oranda } \\
\text { artırmıștır. }\end{array}$ \\
\hline 4 & Bilye-disk & \%25 Cam elyaf/PTFE & $\begin{array}{l}\text { AISI } 420 \\
\text { paslanmaz } \\
\text { çelik }\end{array}$ & $10 \mathrm{~N}$ & $25 \mathrm{~Hz}$ & - & $\begin{array}{l}\text { En düşük sürtünme katsayısı } \\
(0.028) \text { ve en düşük aşınma oranı } \\
\left(5.85 \times 10^{-6} \mathrm{~mm}^{3} \mathrm{Nm}^{-1}\right) \text { deniz suyu } \\
\text { ortamında elde edilmiştir. }\end{array}$ \\
\hline 6 & Pim-disk & $\begin{array}{l}\text { \%20Karbon/PTFE } \\
\text { \%20Bronz/PTFE } \\
\text { \%35Bronz/PTFE }\end{array}$ & - & $\begin{array}{l}10,20,30 \\
N\end{array}$ & $\begin{array}{l}600,800 \\
1000 \\
\text { dev/dak. }\end{array}$ & $\begin{array}{l}2000,3000 \\
4000\end{array}$ & $\begin{array}{l}\text { Artan yük miktarı ile sürtünme } \\
\text { katsayısı ve aşınma oranı artmıștır. } \\
\text { Artan kayma hızı ile sürtünme } \\
\text { katsayısı artarken aşınma oranı } \\
\text { azalmıştır. }\end{array}$ \\
\hline 7 & Bilye-disk & \%60Bronz/PTFE & $\begin{array}{l}\text { AISI } 420 \\
\text { paslanmaz } \\
\text { çelik }\end{array}$ & $10 \mathrm{~N}$ & $25 \mathrm{~Hz}$ & - & $\begin{array}{l}\text { En düşük sürtünme katsayısı } \\
(0.0045) \text { ve en düşük spesifik } \\
\text { aşınma oranı }\left(1.10 \times 10^{-5} \mathrm{~mm}^{3} / \mathrm{Nm}\right) \\
\text { deniz suyu ortamında elde edildiği } \\
\text { belirtilmiștir. }\end{array}$ \\
\hline 8 & Pim-disk & $\begin{array}{l}\text { \%21, 22, 23, } 24 \\
\text { Grafit/PTFE }\end{array}$ & - & $10,20 \mathrm{~N}$ & $\begin{array}{l}190,210 \\
\text { dev/dak. }\end{array}$ & 2000 & $\begin{array}{l}\text { PTFE polimerine ilave edilen grafit } \\
\text { aşınma oranını azaltmıştır. } \\
\text { Optimum aşınma oranı } \% 22 \text { grafit } \\
\text { miktarında } 10 \mathrm{~N} \text { yük ve } 210 \mathrm{dev} / \mathrm{dk} \text {. } \\
\text { kayma hızında elde edilmiștir. }\end{array}$ \\
\hline 9 & Pim-disk & $\begin{array}{l}\% 60 \text { Bronz/PTFE } \\
\% 25 \text { Karbon/PTFE } \\
\% 15 \text { Cam elyaf/PTFE }\end{array}$ & Çelik disk & $\begin{array}{l}20,40,80 \\
\mathrm{~N}\end{array}$ & $1.0 \mathrm{~m} / \mathrm{s}$ & $\begin{array}{l}600,1200 \\
1800\end{array}$ & $\begin{array}{l}\text { Artan kayma mesafesi ve uygulanan } \\
\text { yük ile aşınma oranı artmıştır. Cam } \\
\text { elyaf takviyeli kompozitin bronz ve } \\
\text { karbon elyaf takviyeli kompozite } \\
\text { göre aşınma direnci daha yüksek } \\
\text { elde edilmiștir. }\end{array}$ \\
\hline 10 & Pim-disk & $\begin{array}{l}\text { \%10Grafit/PTFE } \\
\% 15 \text { Grafit/PI }\end{array}$ & $\begin{array}{l}\text { 01 takım } \\
\text { çeliği }\end{array}$ & $6.32 \mathrm{MPa}$ & $1.91 \mathrm{~m} / \mathrm{s}$ & - & $\begin{array}{l}\text { PI kompozit, PTFE kompozite göre } \\
\text { daha yüksek aşınma ve sürtünme } \\
\text { göstermiștir. }\end{array}$ \\
\hline 14 & Pim-disk & \%10PTFE/PA6-PA66 & $\begin{array}{l}\text { E-52100 } \\
\text { çeliği }\end{array}$ & $\begin{array}{l}25,50,75, \\
100 \mathrm{~N}\end{array}$ & $\begin{array}{l}0.5,1.0,1.5 \\
2.0 \mathrm{~m} / \mathrm{s}\end{array}$ & - & $\begin{array}{l}\text { Kayma hızının artması ile aşınma } \\
\text { oranı artmıştır. Yükün artması ile } \\
\text { aşınma hacmi artarken spesifik } \\
\text { așınma oranı azalmıștır. }\end{array}$ \\
\hline 16 & Plaka-disk & $\begin{array}{l}\text { \%5-20PTFE/\%15Cam } \\
\text { elyaf-PA6 } \\
\text { \%5-20ÇYMAPE/\%15Cam } \\
\text { elyaf-PA6 }\end{array}$ & Krom çeliği & $40,100 \mathrm{~N}$ & $\begin{array}{l}200,1500 \\
\text { rpm }\end{array}$ & - & $\begin{array}{l}40 \mathrm{~N} \text { yük ve } 200 \mathrm{dev} / \mathrm{dk} \text {. hızda PTFE } \\
\text { polimerinin matris malzemelerin } \\
\text { tribolojik özellikleri geliştirmede } \\
\text { ÇYMAPE polimerinden daha etkili } \\
\text { olduğu belirtilmiştir. Optimum } \\
\text { aşınma direnci } \% 20 \text { PTFE } \\
\text { içeriğinde, sürtünme katsayısında } \\
\% 30 \text { azalma ve aşınma oranında } \\
\% 29 \text { azalma ile elde edilmiștir. }\end{array}$ \\
\hline 17 & Pim-disk & \%5-40Grafit/PA6 & EN31 çeliği & $\begin{array}{l}5,10,20, \\
30 \mathrm{~N}\end{array}$ & $\begin{array}{l}\text { 1000, 1500, } \\
2000 \\
\text { dev/dak. }\end{array}$ & 1000 & $\begin{array}{l}\text { Artan yük } \text { ile birlikte sürtünme } \\
\text { katsayısı ve aşınma oranı } \\
\text { azalmıştır. } \% 20 \text { grafit katkılı PA6 } \\
\text { kompoziti en iyi tribolojik } \\
\text { özellikleri göstermiștir. }\end{array}$ \\
\hline 18 & Pim-disk & $\begin{array}{l}\text { \%5-30 } \mathrm{Al}_{2} \mathrm{O}_{3} / \mathrm{PA} 6 \\
\% 5-30 \mathrm{Grafit} \mathrm{PA6}\end{array}$ & EN31 çeliği & $\begin{array}{l}5,10,20, \\
30 \mathrm{~N}\end{array}$ & $\begin{array}{l}\text { 1000, } 2000 \\
\text { dev/dak. }\end{array}$ & 1000 & $\begin{array}{l}\text { \%20 grafit ve } \% 30 \mathrm{Al}_{2} \mathrm{O}_{3} \text { içeren PA6 } \\
\text { kompozitleri kuvvetli arayüzey } \\
\text { bağlanması nedeniyle en iyi } \\
\text { tribolojik özellikleri göstermiştir. } \\
\text { Kayma hızının artmasıyla sürtünme } \\
\text { katsayısının ve aşınma oranının } \\
\text { arttığı belirlenmiştir. Artan yük } \\
\text { miktarı ise polimerin aşınma } \\
\text { oranını azaltırken ısı üretimini } \\
\text { artırmıștır. }\end{array}$ \\
\hline 19 & Pim-plaka & $\begin{array}{l}\text { \%10-40Talk/PA6 } \\
\% 5-10-15-20-25 \text { Cam } \\
\text { elyaf/PA6 } \\
\text { Grafit/ÇYYPE/PA6 }\end{array}$ & Krom çeliği & $40,160 \mathrm{~N}$ & $\begin{array}{l}1500 \\
\text { dev/dak. }\end{array}$ & - & $\begin{array}{l}\text { \%15 cam elyaf miktarında } \\
\text { sürtünme katsayısı ve aşınma oranı } \\
\text { azalmıştır. Katı yağlayıcı olarak } \\
\text { ilave edilen grafit ve UHMWPE } \\
\text { sürtünme katsayısını ve aşınma } \\
\text { oranını artırmıștır. }\end{array}$ \\
\hline 20 & Pim-disk & $\begin{array}{l}\text { \%10-15-20-25- } \\
\text { 30Grafit/PA6 }\end{array}$ & EN31 çeliği & $5,10,15 \mathrm{~N}$ & $1.04 \mathrm{~m} / \mathrm{s}$ & 314.2 & $\begin{array}{l}\text { Artan yüke ve grafit oranına bağlı } \\
\text { olarak spesifik aşınma oranın } \\
\text { azaldığı belirlenmiştir. } \\
\text { Çalışmalarında en düșük aşınma } \\
\text { oranı \%25 grafit katkılı PA6 } \\
\text { polimer kompozitinde elde } \\
\text { edilmiștir. }\end{array}$ \\
\hline
\end{tabular}



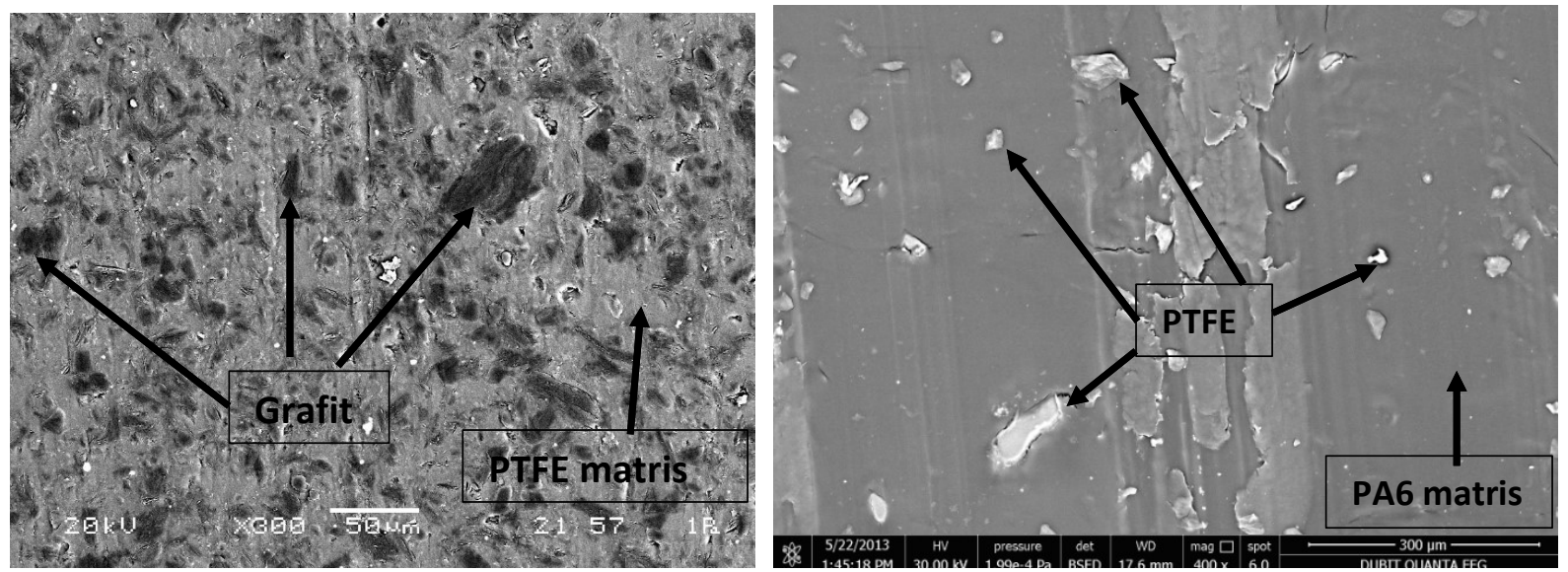

Şekil 1. Deneylerde kullanılan pim-malzemelerin așınma yüzeyi taramalı elektron mikroskop görüntüleri a) $35 \mathrm{Grafit}$ katkılı PTFE polimer kompoziti b) 10PTFE/PA6 polimer karışımı

\section{Materyal ve Metot}

\subsection{Deneylerde kullanılan malzemeler}

Deneylerde kullanılan malzemelerden ağırlıkça \%10PTFE katkılı poliamit 6 polimerler karışımı endüstriyel bir kompound makinasında üretilmiştir. Ana matris malzeme olan poliamit 6 polimeri Belçika'nın Domomid firmasından temin edilmiștir. PTFE katkı ise toz formunda olup DuPONT firmasından temin edilmiştir. PA6/PTFE polimer karıșımı, NRII-75 tip çift vidalı kompound makinasında üretilmiştir. Kompound makinası ısıtıcı sıcaklıkları $220-255^{\circ} \mathrm{C}$ arasında ayarlanmıștır. Triboloji test numuneleri ise özel olarak dizayn edilmiş kalıplarda üretilmiştir. $6 \mathrm{~mm}$ çapında ve $50 \mathrm{~mm}$ uzunluğundaki test numuneleri kalıpta enjeksiyon makinasında basılarak üretilmiștir. Enjeksiyon isitıcı sicaklıkları da $220-250^{\circ} \mathrm{C}$ arasında ayarlanmıștır. Ağırlıkça \%35 grafit katkılı PTFE polimeri ise ticari bir ürün olarak temin edilmiștir. \%35grafit katkılı PTFE polimeri endüstride genel ve standart yöntemler ile üretilmesine rağmen PTFE katkılı PA6 polimeri endüstriyel bir kompound makinasında profesyonel olarak üretilerek alternatif bir malzeme olușturmak ve mekanik/tribolojik performansları açısından endüstride alternatif bir ürün oluşturabilmek için bu çalışma yapılmıştır. Şekil 1 'de, kullanılan grafit ve PTFE katkıların homojen olarak dağıldığını gösteren aşınma yüzeyi taramalı elektron mikroskop resimleri verilmiștir.

\subsection{Sürtünme katsayısı ve spesifik aşınma hızı ölçümü}

Tribolojik deneyler, bir kola sabitlenmiş bir polimer pimin bir elektrik motorundan aldığı hareketle dönen bir AISI 316L paslanmaz çelik diskin birbirine temas ettiği bir aşınma test cihazında gerçekleştirilmiștir. Disk üzerinde pim olacak şekilde özel olarak dizayn edilmiş bir aşınma test cihazının şematik diyagramı Şekil 1'de gösterilmiştir. Deneylerde kullanılan her iki malzemenin pim test numunelerin boyutları $6 \mathrm{~mm}$ çapında ve 50mm uzunluğundadır. Grafit katkılı PTFE polimer kompozit pim malzemeler, revolver tornada hassas bir șekilde ișlenerek așınma test numune ölçülerine getirilmiştir. Aşınma ve sürtünme deneylerinde karşı disk malzeme olarak AISI 316L paslanmaz çelik malzeme kullanılmıştır. Disk malzemeler, $5 \mathrm{~mm}$ kalınlığında ve $90 \mathrm{~mm}$ çapında olacak şekilde önce geleneksel bir tornada işlenmiş ardından ise düzlem yüzey tașlama ișlemlerine maruz bırakılmıștır. Așınma ve sürtünme deneylerinden önce, 35G/PTFE ve 10PTFE/PA6 polimer pim malzemeler ve karşı paslanmaz çelik disk yüzeyleri 1200 nolu zımpara ile zımparalanmıştır. Her test öncesi hem disk yüzeyleri hem de pim yüzeyleri asetonla temizlenip kurutulmuştur.

Tribolojik deneylerde Şekil 2'de șematik resmi verilen pim-disk aşınma test cihazı kullanılmıștır. Şekilde görüldüğü gibi disk malzeme tek yönlü hızı ayarlanabilir bir elektrik motoru ile döndürülmektedir. Şekilde görülen diskin üzerine deneyde kullanılan $5 \mathrm{~mm}$ et kalınlıklı ve $90 \mathrm{~mm}$ çaplı AISI 316L paslanmaz çelik disk monte edilmektedir. Test edilecek pim malzemeler pim tutucu bir mekanizmaya bağlanarak hareketli yükleme koluna monte edilmektedir. Bu yükleme kolu, numuneye yanal yüklerin uygulanmasına izin verebilecek şekilde yataklanmıștır.

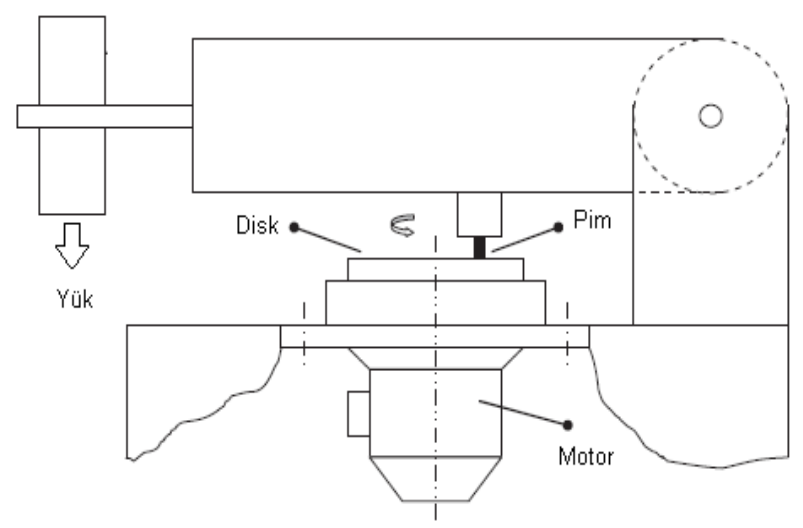

Şekil 2. Deneylerde kullanılan pim-disk aşınma test cihazı 
Deneyler sırasında, sürtünme kuvveti yükleme koluna monte edilmiş bir yük hücresi ile ölçülmektedir. 66 dakikalık deney süresi boyunca her 60 saniyede yaklaşık 1500 veri okunmuş ve bilgisayarda bir Excell programında kaydedilmiștir. Sürtünme kuvveti olarak ifade edilen yanal yükler uygulanan normal yüke bölünerek malzeme çiftinin sürtünme katsayısı belirlenmiştir. Sürtünme katsayısı ( $\mu$ ) Eşitlik 1 [21] kullanılarak hesaplanmıştır. Burada; $\mu$ polimer malzemelerin sürtünme katsayısı, $F_{f}$ deneylerde ölçülen yanal yük ve $F_{N}$ ise normal yüktür.

$$
\mu=\mathrm{Ff} / \mathrm{FN}
$$

Yine deneylerde kullanılan pim malzemelerin aşınma miktarı deney öncesi ve deney sonrası ağırlık farkı alınarak tespit edilmiştir. Pim malzeme ağırlık ölçümleri $1 \times 10^{-4} \mathrm{~g}$ hassasiyetli Precia marka $220 \mathrm{~g}$ kapasiteli bir hassas terazi ile gerçekleştirilmiştir. Malzemelerin spesifik aşınma oranı (Ws) $\left[\mathrm{m}^{2} / \mathrm{N}\right]$ Eşitlik 2 [22] kullanılarak hesaplanmıştır.

$$
W s=\frac{(\Delta V)}{A \times L \times P} \text { veya } W s=\frac{(\Delta m)}{L \times \rho \times F_{N}}
$$

Yukarıdaki formülde; $\Delta \mathrm{V}$ pim numunelerinin aşınma hacmi, $\Delta \mathrm{m}$ deney sonrası ve öncesi kütle kaybı, $\mathrm{A}$ temas alanı, $\rho$ yoğunluk, $\mathrm{P}$ uygulanan basınç, FN normal yük ve $\mathrm{L}$ ise kayma yoludur. $\mathrm{Bu}$ çalışma için seçilen aşınma test parametreleri Tablo 2'de verilmiştir. Tribolojik deneyler, $1.0,1.5$ ve $2.0 \mathrm{~m} / \mathrm{s}$ kayma hızlarında ve $50 \mathrm{~N}$ ve $150 \mathrm{~N}$ yükler altında kuru kayma şartlarında ve oda sıcaklığında gerçekleştirilmiştir. Bu çalışmada, $50 \mathrm{~N}$ ve $150 \mathrm{~N}$ yüklerin seçilmesinin sebebi daha önce PA6 polimeri ile elde edilen tecrübeler neticesindedir. Düşük yükler aşınma miktarının az olmasına sebep olmaktadır. $\mathrm{Bu}$ durum, nem alma özelliği olan polimerin aşınma sonuçlarını olumsuz etkilemektedir. Çok yüksek yüklerin seçilmesi ise pim numunelerin aşırı derecede aşınmasına sebep olmaktadır. Bu sebeple kullanılan yükler ile hızların optimize edilerek seçilmesi deney sonuçlarının daha iyi belirlenmesini sağlamaktadır. Tribolojik deneylerde kullanılan malzemelerin farklı hız ve yüklerdeki spesifik aşınma oranı değerleri $\left(\mathrm{m}^{2} / \mathrm{N}\right)$ hesaplanmış ve sürtünme katsayısı $(\mu)$ değerleri de ölçülmüştür
Tablo 2. Așınma ve sürtünme deney șartları

\begin{tabular}{|l|l|l|}
\hline Test parametreleri & Birimi & Test șartları \\
\hline Disk yüzey pürüzlülüğü $(\mathrm{Ra})$ & $(\mu \mathrm{m})$ & $0.33-0.45$ \\
Kayma yolu & $(\mathrm{m})$ & 2000 \\
Çalıșma sıcaklığı & $\left({ }^{\circ} \mathrm{C}\right)$ & $22 \pm 2$ \\
Ortam nem oranı & $(\%)$ & $56 \pm 2$ \\
Kayma hızı & $(\mathrm{m} / \mathrm{s})$ & $1.0,1.5,2.0$ \\
Uygulanan yük & $(\mathrm{N})$ & 50,150 \\
\hline
\end{tabular}

\section{Bulgular}

Şekil 3'te $50 \mathrm{~N}$ ve $150 \mathrm{~N}$ yük altında 35G/PTFE kompoziti ve 10PTFE/PA6 polimer karışımının farklı hızlardaki aşınma hacminin kayma hızı ile değişimi verilmiştir. Şekilde görüldüğü gibi düşük yük altında (50N) ve artan kayma hızlarında 35G/PTFE polimer kompozitin aşınma hacmi pek değişmezken, $150 \mathrm{~N}$ yükte aşınma hacmi \%35 oranında artış göstermiştir. $50 \mathrm{~N}$ ve $150 \mathrm{~N}$ yük altında kayma hızının $1.0 \mathrm{~m} / \mathrm{s}^{\prime} d e n$ $2.0 \mathrm{~m} / \mathrm{s}$ 'ye çıkarılması ile 10PTFE/PA6 polimer kompozitin aşınma hacmi belirgin şekilde ve lineer olarak artmıştır. $\mathrm{Bu}$ artış, 50N yük altında $\% 22$ oranında elde edilirken 150N yük altında \%37 oranında elde edilmiştir. Bilindiği gibi, aşınma mekanizması kırılma, tribo-kimyasal etkiler ve plastik akış süreçlerini kapsamaktadır. Bunların her birinin hakim olduğu bölgeler arasındaki geçişler, genellikle uygulanan yük ile aşınma oranında değişikliklere neden olmaktadır. Dolayısıyla elde edilen sonuç, yapı özellikleri ve sürtünme süreçlerinde meydana gelen kimyasal etkiler ve karşı disk üzerindeki transfer filmi oluşumu ile yakından ilgilidir [12].

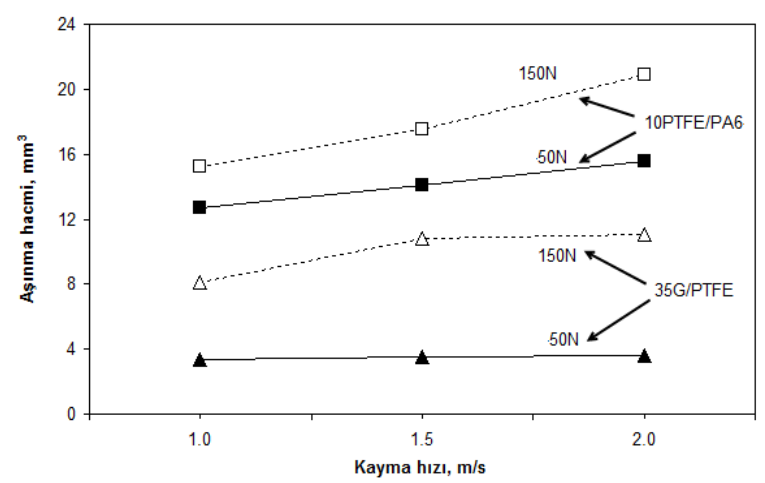

Şekil 3. 35G/PTFE polimer kompoziti ile 10PTFE/PA6 polimer karışımının farklı yüklerdeki așınma hacmi- kayma hızı ilişskisi

\begin{tabular}{|c|c|c|c|c|c|c|c|}
\hline \multirow{3}{*}{$\begin{array}{l}\text { Deneyde kullanılan } \\
\text { malzemeler }\end{array}$} & \multirow[b]{3}{*}{$\begin{array}{l}\text { Yük } \\
(\mathrm{N})\end{array}$} & \multicolumn{6}{|c|}{ Kayma hızı (m/s) } \\
\hline & & \multicolumn{2}{|c|}{1.0} & \multicolumn{2}{|c|}{1.5} & \multicolumn{2}{|c|}{2.0} \\
\hline & & $\begin{array}{c}\text { Spesifik } \\
\text { aşınma oranı } \\
\left(\mathrm{x} 10^{-14} \mathrm{~m}^{2} / \mathrm{N}\right)\end{array}$ & $\begin{array}{c}\text { Sürtünme } \\
\text { katsayısı, } \\
(\mu)\end{array}$ & $\begin{array}{c}\text { Spesifik } \\
\text { aşınma oranı } \\
\left(\mathrm{x} 10^{-14} \mathrm{~m}^{2} / \mathrm{N}\right)\end{array}$ & $\begin{array}{c}\text { Sürtünme } \\
\text { katsayısı, } \\
(\mu)\end{array}$ & $\begin{array}{c}\text { Spesifik } \\
\text { aşınma oranı } \\
\left(\mathrm{m}^{2} / \mathrm{N}\right)\end{array}$ & $\begin{array}{c}\text { Sürtünme } \\
\text { katsayısı, } \\
(\mu)\end{array}$ \\
\hline \multirow{2}{*}{ 35G/PTFE } & 50 & 3.35 & 0.1156 & 3.53 & 0.1352 & 3.63 & 0.1278 \\
\hline & 150 & 2.70 & 0.1456 & 3.61 & 0.1253 & 3.67 & 0.1360 \\
\hline \multirow{2}{*}{ 10PTFE/PA6 } & 50 & 12.7 & 0.2206 & 14.1 & 0.2280 & 15.5 & 0.2226 \\
\hline & 150 & 5.07 & 0.2030 & 5.85 & 0.2080 & 6.97 & 0.1985 \\
\hline
\end{tabular}

Tablo 3. Deneyde kullanılan malzemeler ve deneyler sonucunda elde edilen tribolojik özellikleri 
Tablo 3'te \%35 grafit katkılı PTFE polimer kompoziti ile \%10 grafit katkılı PA6 polimer karışımının 1.0, 1.5 ve $2.0 \mathrm{~m} / \mathrm{s}$ kayma hızları ile 50 ve $150 \mathrm{~N}$ yükler altındaki tribolojik testler sonucunda elde edilen sürtünme katsayısı ile spesifik aşınma oranları sonuçları verilmiştir. Şekil 4'te ise 35G/PTFE polimer kompoziti ve 10PTFE/PA6 polimer karışımının 50N ve $150 \mathrm{~N}$ yükler altında spesifik aşınma oranının uygulanan kayma hızına göre değişimi verilmiştir. Şekilde görüldüğü gibi deneyde kullanılan 35G/PTFE polimer kompoziti ve 10PTFE/PA6 polimer karışımının spesifik aşınma oranı değerleri yaklaşık olarak $10^{-14} \mathrm{~m}^{2} / \mathrm{N}$ civarında bulunmuştur. Kayma hızının artması ile spesifik aşınma oranı artmıştır. Benzer sonuçlar, Raaj ve arkadaşları [3] tarafından yapılan çalışmada da elde edilmiștir. 35G/PTFE polimer kompozitin $50 \mathrm{~N}$ ve $150 \mathrm{~N}$ yük altındaki aşınma oranları, kayma hızının artması ile birlikte sırasıyla $\% 8$ ve \%36 oranlarında artarken, 10PTFE/PA6 polimer karışımının aşınma oranları $\% 22$ ve $\% 37$ oranlarında artmıștır. $1.5 \mathrm{~m} / \mathrm{s}$ kayma hızında ve $150 \mathrm{~N}$ yük altındaki 35G/PTFE kompozitin ve 10PTFE/PA6 polimer karışımının spesifik aşınma oranları karşılaştırıldığında, 35G/PTFE polimer kompozitin 10PTFE/PA6 polimer karışımına göre \%62 oranında daha dirençli olduğu belirlenmiştir. Uygulanan kayma hızı ve yük aralıklarında, en düşük spesifik aşınma oranı $1.0 \mathrm{~m} / \mathrm{s}$ kayma hızı ve $150 \mathrm{~N}$ yük altında $2.70 \times 10^{-14} \mathrm{~m}^{2} / \mathrm{N}$ değeri ile $35 \mathrm{G} / \mathrm{PTFE}$ polimer kompozitinde elde edilirken en yüksek spesifik aşınma oranı $2.0 \mathrm{~m} / \mathrm{s}$ kayma hızı ve $50 \mathrm{~N}$ yük altında $15.5 \times 10^{-14} \mathrm{~m}^{2} / \mathrm{N}$ değeri ile 10PTFE/PA6 polimer karışımında elde edilmiştir. Yüksek kayma hızı ve yük değerlerinde kullanılan katkılar ile birlikte karşı disk yüzeyinde gözle görülebilen ve mikronboyutlu olduğu düşünülen transfer film tabakasının oluşması ve artan kayma hızı ile birlikte daha kolay transfer film tabakasının oluşması aşınmaya dirençli malzemelerin elde edilmesini sağlamıştır.

Şekil 5'te 35G/PTFE polimer kompoziti ve 10PTFE/PA6 polimer karışımının 1.5m/s kayma hızı ve $150 \mathrm{~N}$ yük altındaki sürtünme katsayısı-kayma mesafesi grafiği verilmiștir. 35G/PTFE polimer kompoziti ve 10PTFE/PA6 polimer karışımının sürtünme katsayısı iki aşamada elde edilmiştir. Birinci aşama olan başlangıç aşaması yaklaşık olarak 300 m kayma mesafesi sonrasında sona ermiş ve polimer malzemeler ikinci aşama olan kararlı hal aşamasına geçmiştir. Başlangıç aşamasında, polimer pim malzemelerin yüzeylerinde ve disk yüzeylerinde pürüzlü yüzeyler bulunmaktadır. Bu aşamada pim ve disk yüzeyleri temas etmekte iken kararlı hal aşamasına ulaşıldığında bu pürüzlü yüzeyler oluşan polimer aşınması neticesinde ortadan kaybolmakta ve karşı disk yüzeyi aşınma partikülleri ile kaplanarak transfer film tabakası oluşur. Benzer sonuçlar, Wladyslaw ve arkadaşları [1] tarafindan yapılan çalışmada da elde edilmiştir. Bilindiği gibi grafit, birbirine zayıf Van der Waals kuvvetleri ile bağlanmış ince paralel düzlemler (grafen) oluşturan altıgen halkalardan oluşan tabakalı yapıya sahip katı bir yağlayıcıdır. Kayma süresince, sürtünme kuvvetleri grafit partiküllerinin kayma yönünde hizalanmasına sebep olmaktadır. Grafen plakaları arasındaki zayıf bağ kayma yönünde düşük kayma gerilmelerine neden olurken kayma yönüne dik yönde yüksek basma dayanımı sağlamaktadır [23]. Prakash [2] ve Kumar [8] tarafindan yapılan çalışmalarda da grafit partiküllerinin disk yüzeyinde transfer film tabakası oluşturarak tribolojik özellikleri geliștirdiği belirtilmiștir. PTFE polimerinin ise transfer film tabakası ömrünün çok kısa olduğu dolayısıyla çelik disk yüzeyinde kararlı bir transfer film tabakasının oluşamayacağı belirtilmiştir. PTFE polimerinin kuru sürtünme şartları altında büyük tabakalar/pullar oluşturacağı ve sürtünme prosesi süresince temas bölgesini terk edeceği belirtilmiştir [24].

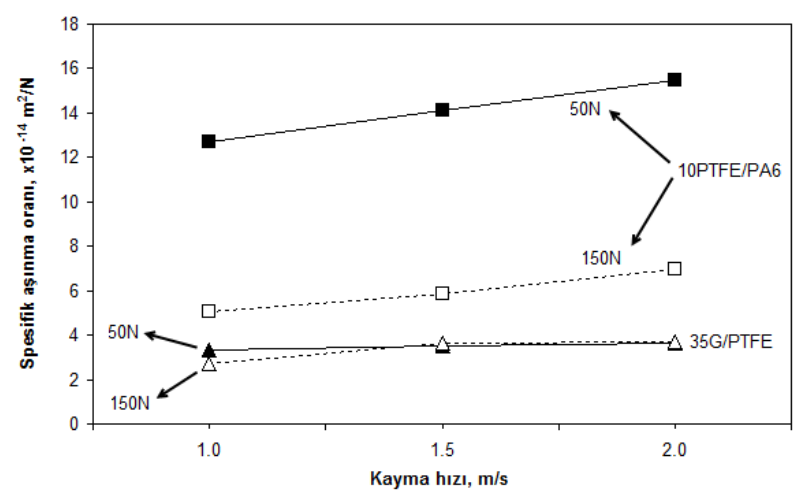

Şekil 4. 35G/PTFE polimer kompoziti ile 10PTFE/PA6 polimer karışımının farklı yüklerdeki spesifik aşınma oranıkayma hızı ilişkisi

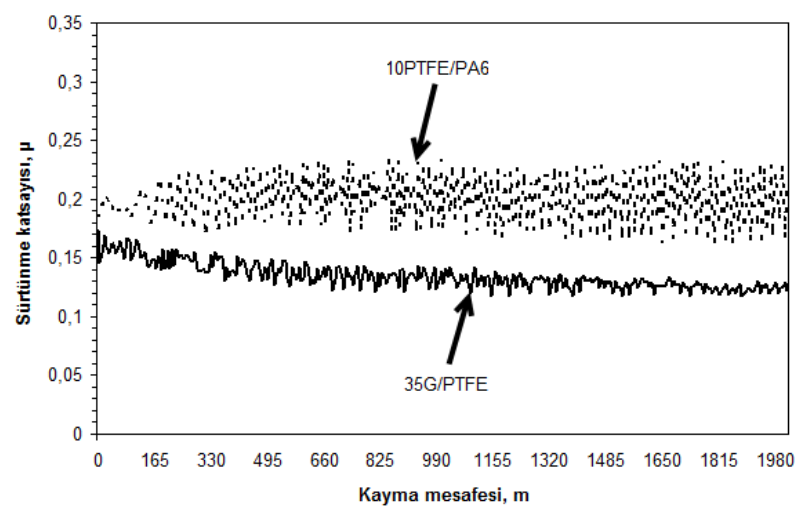

Şekil 5. 35G/PTFE polimer kompoziti ve 10PTFE/PA6 polimer karışımının sürtünme katsayısı-kayma mesafesi ilişkisi (Hız:1.5m/s, Yük:150N)

Şekil 6'da 35G/PTFE polimer kompoziti ile 10PTFE/PA6 polimer karışımının $50 \mathrm{~N}$ ve $150 \mathrm{~N}$ yükler altındaki sürtünme katsayısının uygulanan hıza göre değişimi verilmiştir. Şekilde görüldügü gibi her iki malzeme içinde sürtünme katsayısı değerleri uygulanan kayma hızının artması ile artış göstermiştir. $50 \mathrm{~N}$ yük altında, uygulanan kayma hızının $1.0 \mathrm{~m} / \mathrm{s}^{\prime}$ den $2.0 \mathrm{~m} / \mathrm{s}^{\prime} y e$ artırılması ile 35G/PTFE polimer kompozitinin ve 10PTFE/PA6 polimer karışımının sürtünme katsayıları sırasıyla 
\%17.3 ve \%6.1 oranlarında artmıştır. Uygulanan kayma hızı aralıklarında 35G/PTFE polimer kompozitinin sürtünme katsayısı 0.11 ile 0.13 arasında değişirken 10PTFE/PA6 polimer karışımının sürtünme katsayısı 0.21 ile 0.22 arasında değişim göstermiştir. 150N yük altında ise uygulanan kayma hızının $1.0 \mathrm{~m} / \mathrm{s}^{\prime}$ den $2.0 \mathrm{~m} / \mathrm{s}$ 'ye artırılması ile 35G/PTFE polimer kompoziti ile 10PTFE/PA6 polimer karışımının sürtünme katsayıları sırasıyla $\% 9.6$ ve \%7.0 oranlarında artmıştır. Bunun sebebi ise kayma hızının artması ile polimer ve disk arasındaki temastan dolayı temas noktasındaki malzeme sıcaklığının artması ile açıklanabilir. Bu sıcaklık artışı ile muhtemelen polimer malzemelerin camsı geçiş sıcaklıklarına yakın sıcaklıklara ulaşıldığı düşünülmektedir. $\mathrm{Bu}$ ise muhtemelen polimerin yumuşamasına sebep olmuş ve bunun sonucunda ise sürtünme katsayısının artmasına sebep olmuştur. Benzer bir açılama Reza ve Andreas [10] tarafından yapılan bir çalışmada da ifade edilmiştir. Malzemelerde sıcaklığın artması polimerlerin sertlik ve rijitliği temsil eden elastiklik modülü gibi özelliklerini etkilediğini belirtmişlerdir. Uygulanan yükün sürtünme katsayısı üzerine etkisi incelendiğinde ise yükün artması ile birlikte 35G/PTFE polimer kompozitin sürtünme katsayısının pek değişmediği ancak 10PTFE/PA6 polimer karışımının sürtünme katsayısının hafif bir şekilde azaldığı belirlenmiştir. Temas noktalarında sürtünme nedeniyle oluşan ısı bu durumu açıklayabilir. Aynı zamanda, polimer malzemeler visko-elastik davranış gösteren malzemelerdir ve yük altında deformasyonları da visko-elastiktir. $\mathrm{Bu}$ nedenle, arayüzey sıcaklığı, viskoelastik özellikleri etkileyen gerilim, adhezyon ve transfer film tabakasının değişmesine sebep olabilmektedir. Deneylerde kullanılan yük ve kayma hızı aralıklarında en düşük sürtünme katsayısı $1.0 \mathrm{~m} / \mathrm{s}$ kayma hızı ve $50 \mathrm{~N}$ yük altında 35G/PTFE polimer kompozitinde elde edilirken, en yüksek sürtünme katsayısı ise $1.5 \mathrm{~m} / \mathrm{s}$ kayma hızı ve $50 \mathrm{~N}$ yük altında 10PTFE/PA6 polimer karışımında elde edilmiştir.

Şekil 7'de 35G/PTFE polimer kompoziti ile 10PTFE/PA6 polimer karışımının 1.0 m/s kayma hızı ve $50 \mathrm{~N}$ yük altındaki aşınan pim ve disk yüzeylerinin optik mikroskop görüntüleri verilmiștir. Disk resimleri incelendiğinde deneyde kullanılan her iki polimer türü içinde disk yüzeyinde transfer film tabakasının oluştuğu gözlenmiştir. 10PTFE/PA6 polimer karışımında oluşan transfer film tabakasının düzensiz ve bölgesel olarak oluştuğu ancak 35G/PTFE polimer kompozitinde oluşan transfer film tabakasının daha düzenli ve tüm disk yüzeyini kapsayacak şekilde şekillendiği belirlenmiştir. Oluşan bu transfer film tabakası polimer numune ile disk yüzeyi arasındaki teması keserek sürtünme katsayısının azalmasında ve aşınma direncinin artmasında etkili olmuştur. Pim mikroyapı görüntüleri incelendiğinde ise $1.0 \mathrm{~m} / \mathrm{s}$ kayma hızı ve $50 \mathrm{~N}$ yük altında 10PTFE/PA6 polimer karışımında kayma yönü boyunca oyukların oluştuğu gözlenmiştir. 35G/PTFE polimer kompozitinde ise disk resimlerinde de belirtildiği gibi düzenli bir şekilde oluşan transfer film tabakası nedeniyle daha yumuşak ve düz bir yüzey görüntüsünün oluştuğu belirlenmiştir. Sonuç olarak, grafit katkısının PTFE polimerinin sürtünme katsayısının azaltılmasına ve aşınma direncinin artırılmasına katkı sağlayacak katı yağlayıcı katkılardan birisi olduğu görülmektedir.

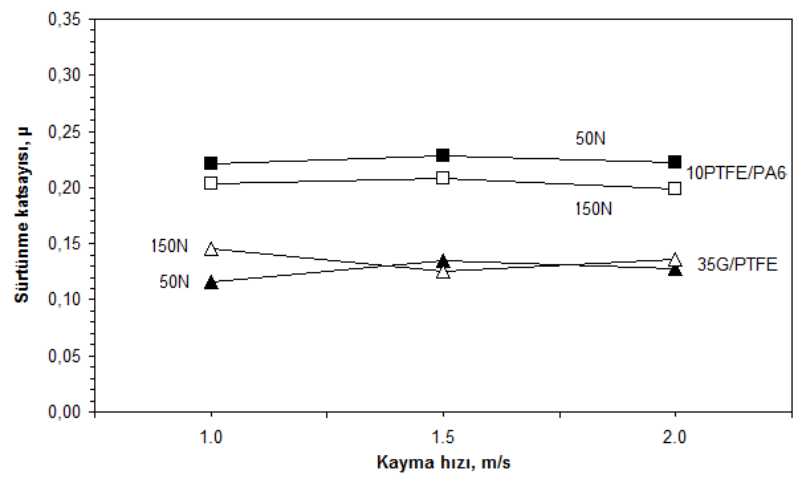

Şekil 6. 35G/PTFE polimer kompoziti ve 10PTFE/PA6 polimer karıșımının farklı yüklerdeki sürtünme katsayısıkayma hızı ilişkisi

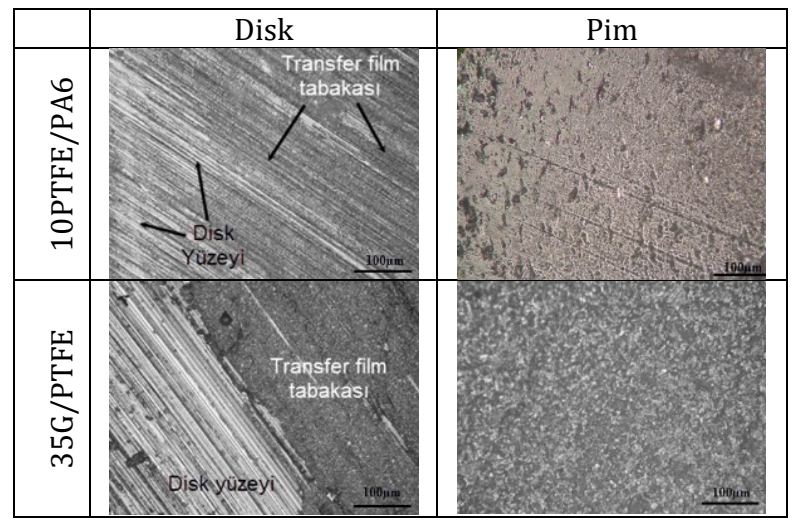

Şekil 7. Așınan polimer pim ve çelik disk yüzeylerinin optik mikroskop mikroyapı görüntüleri (x100) (Hı:1.0m/s, Yük:50N)

\section{Tartışma ve Sonuç}

$\mathrm{Bu}$ triboloji çalışmasında, 35G/PTFE polimer kompoziti ve 10PTFE/PA6 polimer karışımının paslanmaz çelik disk malzemesine karşı çalışmaları durumunda aşağıdaki sonuçlar çıkarılmıştır:

1. Tribolojik testlerde kullanılan 35G/PTFE polimer kompoziti ve 10PTFE/PA6 polimer karıșımının sürtünme katsayıları uygulanan hızın artması ile hafif artmıștır.

2. Uygulanan kayma hızının artırılması ile 35G/PTFE polimer kompoziti ve 10PTFE/PA6 polimerler karışımının sürtünme katsayıları sirasıyla ortalama $\% 17.3$ ve $\% 6.1$ oranlarında artmiştır.

3. En yüksek aşınma oranı $15.5 \times 10^{-14} \mathrm{~m}^{2} / \mathrm{N}$ değeri ile $2.0 \mathrm{~m} / \mathrm{s}$ kayma hızı ve $50 \mathrm{~N}$ yük altında elde $\% 10$ PTFE katkıl poliamit 6 polimer 
karışımında edilirken, en düşük aşınma oranı ise $1.0 \mathrm{~m} / \mathrm{s}$ kayma hızı ve $150 \mathrm{~N}$ yük altında $2.70 \times 10^{-}$ $14 \mathrm{~m}^{2} / \mathrm{N}$ değeri ile $35 \mathrm{G} / \mathrm{PTFE}$ polimer karıșımında elde edilmiştir.

4. Elde edilen deney sonuçlarından, \%35 grafit katkılı PTFE polimer kompoziti, \%10 PTFE katkılı poliamit 6 polimer karışımına göre \%62 oranında daha aşınma dirençli olduğu ve ortalama \%38 oranında ise daha düşük sürtünme katsayısına sahip olduğu tespit edilmiştir.

5. Bu sebeple, așınma ve sürtünme deney sonuçlarına göre triboloji deneylerinde kullanılan yük ve hız aralıklarında \%35 grafit katkılı PTFE polimer kompoziti rulmanlı yatak uygulamalarında kullanım için daha uygun malzeme olduğu tespit edilmiştir.

\section{Etik Beyanı/Declaration of Ethical Code}

Bu çalışmada, "Yükseköğretim Kurumları Bilimsel Araștırma ve Yayın Etiği Yönergesi" kapsamında uyulması gerekli tüm kurallara uyulduğunu, bahsi geçen yönergenin "Bilimsel Araștırma ve Yayın Etiğine Aykırı Eylemler" başlı̆̆ı altında belirtilen eylemlerden hiçbirinin gerçekleștirilmediğini taahhüt ederiz.

\section{Kaynakça}

[1] Wladyslaw, S., Slawomir, K., Adrian, B., Tomasz. K. 2018. Analysis of tribological properties of selected PTFE-based polymer composites in a sliding interaction with aluminium oxide (Al203). Tribologia, 4, 107-112.

[2] Prakash, S. T., Avinash, H. S., Amit Kumar, H., Ramswamy, M. P. 2017. Effect of Graphite on Tribological Behaviour of PTFE Composites. International Journal of Innovative Research in Science, Engineering and Technology, 6(12), 22700-22705.

[3] Raaj, K.R. A., Sriram, S., Harikiran, R. R., Yenugadhati, P. D. 2018. Experimental investigation on influence of molybdenum content on tribological properties of hybrid PTFE composite. Emerging Trends in Mechanical Engineering, AIP Conf. Proc. 2080, 020017-1-020017-7.

[4] Mohammad, J. K., Wani, M. F. Rajat, G. 2018. Tribological properties of glass fiber filled polytetrafluoroethylene sliding against stainless steel under dry and aqueous environments: enhanced tribological performance in sea water. Mater. Res. Express, 5,055309 .

[5] Sujuan, Y., Zeng, X. 2014. Tribological Properties of PTFE and PTFE Composites at Different Temperatures. Tribology Transactions, 57(3), 382-386.

[6] Prashant, B. P., Deore, E. R. 2015. Friction and Wear Behaviour of PTFE \& its Composite in Dry
Conditions. International Journal of Engıneerıng Research \& Technology, 4(12), 306-314.

[7] Khan, M. J., Wani, M. F., Gupta, R. 2018. Tribological properties of bronze filled PTFE under dry sliding conditions and aqueous environments (distilled water and sea water). International Journal of Surface Science and Engineering, 12(5/6). 348 - 364

[8] Kumar, P. S., Madhu, S. V., Vaishak, V. N., Deepthi, Y. P. 2019. Experimental investigation on tribological properties of PTFE based composite. AIP Conf. Proc. 2148, 030023-1030023-6.

[9] Şahin, Y., Mirzayev, H. 2015. Wear characteristics of polymer-based composites. Mechanics of Composite Materials, 51(5), 543554.

[10] Reza, G., Andreas A. P. 2019. Tribological performance of graphite-filled polyimide and PTFE composites in oil-lubricated three-body abrasive conditions. Wear, 436-437, 203044.

[11] Neis, P. D., Ferreira, N. F., Poletto, J.C., Sukumaran, J., Ando, M., Zhang, Y. 2017. Tribological behavior of polyamide- 6 plastics and their potential use in industrial applications. Wear, 376-377, 1391-1398.

[12] Unal, H., Mimaroglu, A. 2012. Friction and wear performance of polyamide 6 and graphite and wax polyamide 6 composites under dry sliding conditions. Wear, 289, 132-137.

[13] Unal, H., Esmer, K., Abdullah, M. 2013. Mechanical, electrical and tribological properties of graphite filled polyamide- 6 composite materials. Journal of Polymer Engineering, 33(4), 351-355.

[14] Umesh, G. L., Krishna Prasad, N. J., Rudresh, B. M., Lingesh, B. V. 2020. Impact of sliding load and velocity on tribological response of PTFE filled polyamide 66 and polyamide 6(PA66/PA6) blend thermoplastic composites. AIP Conference Proceedings, 2274, 030005.

[15] Li., J. 2009. Friction and wear properties of PA6 filled PTFE composites under oil lubrication. Current Applied Physics, 9, 14451449.

[16] Du-Xin, L., Yi-Lan, Y., Xin, D., Wen-Juan, L., Ying, X. 2013. Tribological properties of solid lubricants filled glass fiber reinforced polyamide 6 composites. Materials \& Design, 46, 809-815.

[17] Kumar, S. S., Kanagaraj, G. 2016. Investigation on Mechanical and Tribological Behaviors of PA6 and Graphite-Reinforced PA6 Polymer Composites. Arabian Journal for Science and Engineering. 1-11. 
[18] Satheeskumar, S., Kanagaraj, G. 2016. Experimental investigation on tribological behaviours of PA6, PA6-reinforced $\mathrm{Al} 203$ and PA6-reinforced graphite polymer composites. Bulletin of Materials Science, 39(6), 1467-1481.

[19] Yi-Lan, Y., Du-Xin, L., Gao-Jie, S., Ruo-Yun, L., Xin, D. 2016. Improvement in the tribological properties of polyamide 6: Talc, glass fiber,graphite, and ultrahigh-molecular-weight polyethylene. Journal of Thermoplastic Composite Materials, 29(4), 494-507.

[20] Srinivas, C. L., Sarcar, M. M. M., Suman, K. N. S. 2012. Abrasive wear properties of graphite filled PA6 polymer composites. International Journal of Mechanical Engineering and Robotics Research, 1(3), 157-162.

[21] Jianping, G., Luedtke, W.D., Gourdon, D., Ruths, M., Israelachvili, J. N., Landman, U. 2004. Frictional Forces and Amontons' Law: From the
Molecular to the Macroscopic Scale. The Journal of Physical Chemistry B, 108, 3410-3425.

[22] Gaurav, A., Amar, P., Rajesh, K.S. 2013. Parametric Optimization and Three-Body Abrasive Wear Behavior of Sic Filled Chopped Glass Fiber Reinforced Epoxy Composites . International Journal of Composite Material, $3(2), 32-38$.

[23] Suresha, B., Chandramohan, G., Renukappa, N.M., Siddaramaiah, H. 2007. Mechanical and Tribological Properties of Glass-Epoxy Composites with and Without Graphite Particulate Filler. Journal of Applied Polymer Science, 103, 2472-2480.

[24] Yunxia, W., Fengyuan, Y. 2006. Wear Tribological properties of transfer films of PTFE-based composites. Wear, 261(11-12), 1359-1366. 